\title{
Genitourinary trauma in Canada: An introduction and overview
}

\author{
Keith F. Rourke, MD, FRCSC'; Ron Kodama, MD, FRCSC ${ }^{2}$ \\ 'Division of Urology, University of Alberta, Edmonton, AB, Canada; '2Division of Urology, University of Toronto, Toronto, ON, Canada
}

Cite as: Can Urol Assoc J 2019;13(6Supp|4):S44-5 http://dx.doi.org/10.5489/cuaj.5929

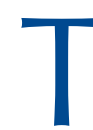

- rauma exerts a substantial human toll and is also (sadly) a growth industry. ${ }^{1}$ For example, trauma is the sixth leading cause of death worldwide and in Canada injury accounts for 15866 deaths per year., ${ }^{2,3}$ Most worrisome is the fact that trauma is the now leading cause of death among young adults worldwide and in Canada is the leading cause of death for people from ages $1-44 .^{2,3}$ In this demographic, trauma results in the loss of more productive work years than cancer and heart disease combined. ${ }^{3}$ While more common in young adults, trauma is not exclusive to this population. In fact, the largest recent increase in trauma has occurred among the baby boomers. ${ }^{1}$ It seems nobody is safe from the scourge of trauma.

In addition to the substantial human impact, trauma has a significant economic burden. Preventable injuries cost Canadians more than $\$ 26.8$ billion a year. ${ }^{3}$ These costs are rising; the economic cost of injury in Canada has increased by $35 \%$ since $2004 .^{3}$ By 2035, injuries will cost Canadians $\$ 75$ billion a year, an increase of $180 \%$. There is no doubt that trauma is a serious public health concern with significant societal and economic costs. ${ }^{3}$

Any aspect of the genitourinary system can be injured. Kidneys are the most commonly affected genitourinary organ; kidney injury occurs in approximately $10 \%$ of major abdominal trauma. ${ }^{4}$ In Canada, renal injury is typically related to blunt trauma sustained during motor vehicle collisions (MVCs). ${ }^{5}$ Over the last 20 years, treatment of renal trauma has become non-operative in the vast majority of cases. ${ }^{5}$ Ureteral trauma, on the other hand, is relatively rare and mainly related to iatrogenic injuries during pelvic surgery or, less commonly, penetrating trauma due to stabbing or gunshot wounds. ${ }^{6}$ Bladder trauma is most commonly associated with pelvic fracture and most often sustained during MVCs. ${ }^{7}$ Urethral injuries can involve either the anterior or those associated with pelvic fractures (PFUI). ${ }^{8}$ Anterior urethral injuries are most commonly related to blunt "straddle" trauma. ${ }^{7,9}$ Genital trauma occurs most commonly in males and is more likely to be isolated to the genitourinary tract. ${ }^{10}$ Unfortunately, genital injuries are also more likely to be misdiagnosed and undertreated owing to a general lack of awareness regarding these types of injuries.

In general, traumatic injuries can be classified by mechanism, degree (partial vs. complete), severity, location, or patient demographic. The Injury Severity Score (ISS) is a well-established scale used commonly to stratify the severity of multisystem trauma. ${ }^{11}$ A major trauma is defined as an ISS greater than 15. This scale correlates with mortality, morbidity, and duration of hospitalization after trauma. ${ }^{12}$ With specific regard to genitourinary injury, there are several classifications in existence that have been used to further stratify these injuries. The most commonly used classification system was developed by the American Association for the Surgery of Trauma (AAST). The AAST has published injury scoring scales for the majority of genitourinary injuries (http://www. aast.org/library/traumatools/injuryscoringscales.aspx). ${ }^{13}$

Most urological injuries occur in the context of multisystem trauma, which requires effective collaboration and communication with the trauma team and other surgical colleagues. While not usually the primary trauma physician, the urologist is an important member of the trauma team when urological injuries occur. The initial emergency assessment of the trauma patient is usually carried out by emergency and trauma team staff with the primary goal of stabilization and resuscitation of the patient. Once the patient is stabilized and life-threatening injuries are addressed, accurate, prompt diagnosis and efficient treatment is critical. Thus, treatment of acute urological injuries requires effective communication, flexibility, and knowledge of damage control principles in order to achieve hemostasis and urinary drainage, especially when treating unstable and severely injured patients.

Effectively treating genitourinary trauma requires familiarity with both open surgical techniques and minimally invasive techniques. Blunt injuries are usually characterized by organ contusion and acute hemorrhage within and around the affected structure. Thus, blunt trauma injuries are often relatively contained and are more often able to be managed conservatively. In contrast, the extent of damage caused by penetrating trauma can be quite variable and depends on the velocity and associated energy of the source. In penetrating injuries, it is important (whenever possible) to obtain infor- 
mation on the caliber of the firearm (in gunshot wounds) or the length of the weapon (in stabbings). High-velocity injuries are seldom isolated and often inflict substantial damage due to the large amounts of transmitted energy with associated cavitation and collateral damage. In low-velocity injuries, the damage is usually confined to the path of the projectile. In either event, penetrating trauma more often requires operative intervention.

The majority of urologists across Canada are exposed to genitourinary trauma to varying degrees. Our role in trauma care is to ensure genitourinary injuries are promptly recognized and accurately diagnosed. The consequences of misdiagnosis are often substantial and result in significant patient morbidity. Our primary treatment goal is to preserve genitourinary tract function whenever possible. In order to do this effectively, it is essential that urologists are well-versed in the diagnosis and management of genitourinary trauma. To improve the diagnosis and treatment of genitourinary trauma, both the American Urological Association and the European Association of Urology have developed guidelines on the subject. ${ }^{14,15}$ However, Canada has unique differences in healthcare delivery when compared to other nations and it can be challenging to implement these recommendations into Canadian urological practice.

This supplement of the Canadian Urological Association Journal focuses on management of genitourinary trauma in the Canadian setting. The authors discuss the existing guidelines on genitourinary trauma and place these guidelines in a Canadian context using a case-based format. We hope you find this supplement informative and helpful when managing these often-overlooked conditions.

Competing interests: Dr. Rourke has participated in advisory board meetings for and is a shareholder of Boston Scientific; and has participated in clinical trials supported by Red Leaf Medical. Dr. Kodama reports no competing personal or financial conflicts.

\section{References}

1. Rhee P, Joseph B, Pandit V, et al. Increasing trauma deaths in the United States. Ann Surg 2014;260:1321. https://doi.org/10.1097/SLA.0000000000000600

2. Centers for Disease Control and Prevention: Injury prevention \& control: Data \& statistics. 20107; http://www.cdc.gov/injury/wisqars/LeadingCauses.html. Accessed Jan. 28, 2019.

3. Parachute. The cost of injury in Canada. Parachute: Toronto, ON. 2015, Version 2.2-3 September 2015. Accessed Feb. 10, 2019.

4. Bruce $L M$, Croce MA, Santaniello JM, et al. Blunt renal artery injury: Incidence, diagnosis, and management. Am Surg 2001;67:550-4.

5. Mann U, Zemp L, Rourke KF. Contemporary management of renal trauma in Canada: A 10-year experience at a level 1 trauma centre. Can Urol Assoc J 2018 Nov 5. [Epub ahead of print] https://doi.org/10.5489/cuai.5581

6. Pereira BM, Ogilvie MP, Gomez-Rodriguez $\mathrm{JC}$, et al. A review of ureteral injuries after external trauma. Scand J Trauma Resusc Emerg Med 2010;18:1-11. https://doi.org/10.1186/1757-7241-18-6

7. Biurlin MA, Fantus RJ, Mellett MM, et al. Genitourinary injuries in pelvic fracture morbidity and mortality using the National Trauma Data Bank. J Trauma 2009;67:1033-9. https://doi.org/10.1097/ TA.0b013e3181bb8d6c

8. Chapple C, Barbagli G, Jordan G, et al. Consensus statement on urethral trauma. BJU Int 2004;93:1195202. https://doi.org/10.1111/i.1464-410x.2004.04805.x

9. Elgammal MA. Straddle injuries to the bulbar urethra: Management and outcome in 53 patients. Int Braz J Urol 2009;35:450-8. https://doi.org/10.1590/S1677-55382009000400009

10. Phonsombat S, Master VA, McAninch JW. Penetrating external genital trauma: A 30-year, single-institution experience. J Urol 2008;180:192-5. https://doi.org/10.1016/i.juro.2008.03.041

11. Baker SP, O'Neill B, Haddon W, et al. The Injury Severity Score: A method for describing patients with multiple injuries and evaluating emergency care. J Trauma 1974;14:187-96. https://doi.org/10.1097/00005373-197403000-00001

12. Orhon R, Eren SH, Karadayı S, et al. Comparison of trauma scores for predicting mortality and morbidity on trauma patients. Ulus Travma Acil Cerrahi Derg 2014;20:258-64. https://doi.org/10.5505/ tijes.2014.22725

13. Moore EE, Shackford SR, Pachter HL, et al. Organ injury scaling: Spleen, liver, and kidney. J Trauma 1989;29:1664-6. https://doi.org/10.1097/00005373-198912000-00013

14. Morey AF, Brandes S, Dugi DD 3rd, et al. Urotrauma: AUA guideline. J Urol 2014;192:327-35. htrps://doi.org/10.1016/i.juro.2014.05.004

15. Summerton DJ, Diakovic N, Kitrey ND, et al. Guidelines on urological trauma. 2015 March Available at: http://uroweb.org/guideline/urological-trauma. Accessed Feb. 2, 2019).

Correspondence: Dr. Keith F. Rourke, Division of Urology, University of Alberta, Edmonton, AB, Canada; krourke@ualberta.ca 